\title{
Oral contraceptives modify DNA methylation and monocyte-derived macrophage function
}

\author{
Ilaria Campesi ${ }^{1,2^{*}}$, Manuela Sanna ${ }^{1,2}$, Angelo Zinellu ${ }^{3,4}$, Ciriaco Carru ${ }^{1,4}$, Laura Rubattu ${ }^{5}$, Pamela Bulzomi ${ }^{6}$, \\ Giuseppe Seghieri ${ }^{7}$, Giancarlo Tonolo ${ }^{8}$, Mario Palermo ${ }^{9}$, Giuseppe Rosano ${ }^{10}$, Maria Marino ${ }^{6}$ and Flavia Franconi ${ }^{1,2}$
}

\begin{abstract}
Background: Fertile women may be encouraged to use contraception during clinical trials to avoid potential drug effects on fetuses. However, hormonal contraception interferes with pharmacokinetics and pharmacodynamics and modifies internal milieus. Macrophages depend on the milieu to which they are exposed. Therefore, we assessed whether macrophage function would be affected by the use of combined oral contraceptives (OCs) and if this influence depended on the androgenic or non-androgenic properties of progestin.
\end{abstract}

Methods: Healthy adult women were enrolled and stratified into two groups: women who did not use OCs (Fs) and women treated with OCS (FOCs). FOCs were further stratified as a function of androgenic (FOCA ${ }^{+}$) and nonandrogenic (FOCA') properties of progestins. Routine hematological, biochemical, inflammatory and endothelial dysfunction parameters were measured. Monocyte-derived macrophages (MDMs) were evaluated for the expression and activity of estrogen receptors and androgen receptors, and release of tumor necrosis factor $\alpha$ $(\mathrm{TNF} \alpha)$ was measured from unstimulated and lipopolysaccharide-stimulated cells.

Results: As is already known, the use of OCs changed numerous parameters: the number of lymphocytes, iron levels, total iron-binding capacity of transferrin, triglycerides, high-density lipoprotein, total cholesterol, and Creactive protein increased, while prothrombin time and alkaline phosphatase decreased. Hormonal levels also varied: cortisol was higher in FOCs, while luteinizing hormone, follicle-stimulating hormone, and testosterone were lower in FOCs. Asymmetric dimethylarginine, an index of endothelial function, was lower in FOC than in Fs, as were cysteine and bilirubin. The androgenic properties of progestins affected the activity of OCs: in particular, white blood cell count, hemoglobin, high-density lipoprotein and calcium were higher in FOCA than in FOCA ${ }^{+}$, whereas percentage oxygen saturation and $\gamma$-glutamyl transpeptidase were lower in FOCA than in FOCA ${ }^{+}$. Importantly, FOCs had a lower global DNA methylation, indicating that OC may have epigenetic effects on gene expression. OC did not modify the expression of androgen receptor but increased estrogen receptor $\alpha$ expression, more considerably in $\mathrm{FOCA}^{+}$, and decreased estrogen receptor $\beta$, more considerably in FOCA'. Importantly, the activation state of estrogen receptor $\beta$ in FOCs was decreased, while estrogen receptor $\alpha$ was not active in either Fs or FOCs. Unstimulated MDMs obtained from FOCs showed higher release of TNFa in comparison with Fs. After lipopolysaccharide stimulation, the release of TNF $\alpha$ was significantly higher in Fs than in FOCs.

Conclusions: OC use induced many changes in hematological and plasmatic markers, modifying hormonal levels, endothelial function, inflammation index and some redox state parameters, producing a perturbation of the internal milieu that impacted macrophagic function. In fact, different levels of estrogen receptor expression and release of TNF $\alpha$ were observed in macrophages derived from OC users. Some of the above activities were linked to the androgenic properties of progestin. Even though it is not known whether these effects are reversible, the results indicate that to avoid potential skewing of results only a single type of OC should be used during a single clinical trial.

\footnotetext{
* Correspondence: ilacampesi79@yahoo.it

${ }^{1}$ National Laboratory of Sex-Gender Medicine of the National Institute of

Biostructures and Biosystems, Osilo, Italy

Full list of author information is available at the end of the article
} 
Keywords: androgenic and non-androgenic progestin, combined oral contraceptive, estrogen receptors, global DNA methylation, monocyte-derived macrophages, TNFa

\section{Background}

The US Food and Drug Administration encourages the enrolment of women in clinical trials that test the efficacy and safety of pharmacological treatments [1,2]. The protocol designs emphasize the need for contraception for women of childbearing potential who participate in drug trials. Certain aspects of the contraceptive requirements for such studies do not appear to have been sufficiently considered, including the fact that hormonal contraception may interfere with pharmacokinetics or even pharmacodynamics [3]. In this context, it is important to remember that sexual hormone receptors behave as transcription factors [4] and that oral contraceptives (OCs) change the endogenous milieu by varying the activity of the pituitary-ovarian [5] and hypothalamus-pituitary-adrenal axes [6]. In addition, OCs can induce subclinical abnormalities in carbohydrate metabolism $[7,8]$, can modify lipid metabolism [9], and are associated with elevation of C-reactive protein [10]. OCs decrease symmetric methylarginine and asymmetric dimethylarginine [11], the latter being an inhibitor of nitric oxide and an index of endothelial dysfunction [12]. OC-induced variations may increase the risk of venous thromboembolism $[13,14]$ and elevate the prevalence of atherosclerosis and its complications in young, apparently healthy women $[15,16]$.

Macrophages play crucial roles in atherosclerosis and immunity $[17,18]$ and are uniquely dependent on the milieu to which they are exposed [19], which, as already mentioned, can in turn be modified by OCs $[5,6,9-11,13,14]$. Importantly, monocyte-derived macrophages (MDMs) express estrogen and androgen receptors [20].

Therefore, we assumed that the variation of internal milieu induced by OCs may affect the function of macrophages. For this reason we studied the influence of OCs on MDM function including the expression and the activity of estrogen and androgen receptors, together with the typical macrophage function of release of tumor necrosis factor $\alpha$ (TNF $\alpha)$ and total DNA methylation in blood cells. We selected combined OCs, which are the most commonly used birth control methods across the world [21], and also considered the androgenic or non-androgenic properties of progestin [22].

\section{Results}

\section{Evaluation of the effect of OCs on routine hematological} and biochemical tests

Women who had not used OCs for at least 3 months to ensure a sufficient washout period (Fs) and women treated with OCs for at least 3 months (FOCs) were matched for weight, body mass index and age (Table 1). As previously reported [10,23-26], FOCs had higher number of lymphocytes and higher levels of iron, total iron-binding capacity of transferrin, triglycerides, highdensity lipoprotein, total cholesterol, and C-reactive protein than non-users, whereas prothrombin time and alkaline phosphatase were less than in Fs (data not shown).

When FOCs were stratified as a function of the androgenic $\left(\mathrm{FOCA}^{+}\right)$and non-androgenic $\left(\mathrm{FOCA}^{-}\right)$properties of the progestins, we observed that white blood cell count, hemoglobin, high-density lipoprotein and calcium were higher in $\mathrm{FOCA}^{-}$than in $\mathrm{FOCA}^{+}$, whereas percentage saturation and $\gamma$-glutamyl transpeptidase were lower in $\mathrm{FOCA}^{-}$than in $\mathrm{FOCA}^{+}$, indicating that these parameters are influenced by the androgenic properties of progestin. Finally, triglycerides tended to be higher in FOCA $^{-}$than in FOCA ${ }^{+}$(Table 1).

Red blood cell count, hematocrit, mean corpuscular volume, ferritin, and the numbers of neutrophils, monocytes, eosinophils, basophils and platelets did not present any significant differences between Fs and FOCs or between $\mathrm{FOCA}^{-}$and $\mathrm{FOCA}^{+}$(data not shown).

\section{Hormonal parameters}

Hormonal statuses are shown in Table 2. FOCs, as expected, had lower testosterone, luteinizing hormone, and follicle-stimulating hormone; estradiol in many cases was under the detection limit. Cortisol was significantly higher in FOCs than in Fs. Finally, thyroid-stimulating hormone was significantly higher in $\mathrm{FOCA}^{-}$than in $\mathrm{FOCA}^{+}$, although it did not significantly differ between Fs and FOCs.

\section{Endothelial function}

Asymmetric dimethylarginine and arginine were lower in FOCs than in Fs, whereas the asymmetric dimethylarginine/arginine ratio was higher in FOCs than in Fs. Finally, symmetric dimethylarginine was similar between Fs and FOCs. Consequently, the asymmetric dimethylarginine/symmetric dimethylarginine ratio was decreased in FOCs, whereas the asymmetric dimethylarginine/arginine ratio was increased in FOCs (Table 3). Importantly, these variations were independent of the androgenic properties of progestin.

\section{Oxidative and inflammatory parameters}

Because variations in redox state have been implicated in many diseases, we investigated oxidative stress 
Table 1 Main characteristics of each subgroup of females

\begin{tabular}{|c|c|c|c|c|c|c|}
\hline Characteristic & Fs $(n=85)$ & FOCs $(n=77)$ & $\begin{array}{c}P \\
\text { value }\end{array}$ & $\mathrm{FOCA}^{+}(n=33)$ & FOCA $^{\text {to }}(n=44)$ & $\begin{array}{c}P \\
\text { value }\end{array}$ \\
\hline Age (years) & $27.0(18.0$ to 40.0$)$ & $27.0(20.0$ to 39.0$)$ & NS & $28.0(20.0$ to 39.0$)$ & 26.0 (20.0 to 39.0$)$ & NS \\
\hline Weight (kg) & 53.0 (38.0 to 78.0$)$ & $54.0(43.0$ to 75.0$)$ & NS & $54.0(45.0$ to 70.0$)$ & 55.0 (43.0 to 75.0$)$ & NS \\
\hline Body mass index $\left(\mathrm{kg} / \mathrm{cm}^{2}\right)$ & 20.2 (17.0 to 28.0$)$ & $21.0(17.0$ to 28.0$)$ & NS & $21.5 \pm 2.1$ & $21.1 \pm 2.4$ & NS \\
\hline Hemoglobin $(\mathrm{g} / \mathrm{dl})$ & $12.7 \pm 1.1$ & $12.6 \pm 1.0$ & NS & $12.4 \pm 1.0$ & $12.8 \pm 0.9$ & 0.044 \\
\hline Saturation (\%) & $24.8 \pm 11.5, n=63$ & $22.8 \pm 10.2, n=62$ & NS & 25.1 (3.7 to 44.5$)$ & $16.0(5.5$ to 51.9$)$ & 0.005 \\
\hline White blood cells ( $10^{9}$ cells/l) & 6.5 (3.62 to 11.7$)$ & $6.8(4.1$ to 12.9$)$ & NS & $6.4 \pm 1.6$ & $7.1 \pm 1.4$ & 0.031 \\
\hline High-density lipoprotein (mg/dl) & $60.9 \pm 11.2$ & $69.3 \pm 13.5$ & $<0.001$ & $65.0 \pm 11.6$ & $72.6 \pm 14.1$ & 0.014 \\
\hline Low-density lipoprotein (mg/dl) & 108.5 (68.0 to 166.0$)$ & 111.0 (35.0 to 229.0) & NS & 114.5 (70.0 to 229.0$)$ & 108.5 (35.0 to 193.0$)$ & NS \\
\hline $\begin{array}{l}\text { High-density/low-density } \\
\text { lipoprotein }\end{array}$ & 0.6 (0.3 to 1.3$)$ & $0.6(0.2$ to 2.0$)$ & NS & $0.6(0.2$ to 0.9$)$ & 0.6 (0.3 to 2.0$)$ & NS \\
\hline Triglycerides (mg/dl) & 68.0 (33.0 to 205.0) & 90.5 (42.0 to 236.0) & $<0.001$ & 83.0 (42.0 to 174.0$)$ & 99.5 (48.0 to 236.0) & NS \\
\hline Glycaemia (mg/dl) & 76.0 (30.0 to 110.0$)$ & 77.0 (50.0 to 93.0) & NS & $73.7 \pm 9.4$ & $77.6 \pm 8.3$ & NS \\
\hline Creatinine $(\mathrm{mg} / \mathrm{dl})$ & 0.7 (0.6 to 0.9$)$ & 0.7 (0.6 to 1.0$)$ & NS & 0.7 (0.6 to 1.0$)$ & 0.71 (0.62 to 0.87 ) & NS \\
\hline Creatinine clearance (ml/min) & $101.9 \pm 16.3$ & $102.3 \pm 14.6$ & NS & $99.92 \pm 14.23$ & $104.08 \pm 14.88$ & NS \\
\hline Uric acid (mg/dl) & $3.6 \pm 0.9$ & $3.4 \pm 0.8$ & NS & $3.3 \pm 0.9$ & $3.4 \pm 0.8$ & NS \\
\hline Urea $(\mathrm{mg} / \mathrm{dl})$ & $27.5(14.8$ to 55.1$)$ & 28.4 (18.4 to 47.2$)$ & NS & $29.7 \pm 7.8$ & $28.8 \pm 6.1$ & NS \\
\hline Total bilirubin (mg/dl) & $0.5(0.2$ to 2.1$)$ & 0.4 (0.10 to 1.9$)$ & $<0.001$ & 0.5 (0.1 to 0.9$)$ & $0.4(0.2$ to 1.93$)$ & NS \\
\hline Alkaline phosphatase (U/l) & 59.0 (38.0 to 115.0$)$ & 55.0 (34.0 to 99.0$)$ & 0.029 & $53.4 \pm 10.1$ & $56.9 \pm 14.6$ & NS \\
\hline Aspartate aminotransferase (U/I) & 19.0 (12.0 to 39.0$)$ & $18.0(10.0$ to 60.0$)$ & NS & $18.0(11.0$ to 29.0$)$ & $18.0(10.0$ to 60.0$)$ & NS \\
\hline Alanine aminotransferase (U/I) & $17.0(6.0$ to 64.0$)$ & 15.0 (6.0 to 38.0$)$ & NS & $15.0(6.0$ to 38.0$)$ & $15.0(7.0$ to 31.0$)$ & NS \\
\hline$\gamma$-Glutamyl transpeptidase $(\mathrm{U} / \mathrm{l})$ & 15.0 (7.0 to 98.0$)$ & 14.0 (7.0 to 34.0$)$ & 0.018 & 15.0 (7.0 to 30.0$)$ & $12.0(7.0$ to 34.0$)$ & 0.024 \\
\hline Calcium (mg/dl) & $9.4(8.3$ to 10.4$)(80)$ & 9.4 (8.4 to 10.1) & NS & $9.2 \pm 0.4$ & $9.5 \pm 0.4$ & 0.003 \\
\hline Sodium (mEq/l) & $140.0(134.0$ to 146.0$)$ & $140.0(135.0$ to 147.0$)$ & NS & $\begin{array}{c}140.0(135.0 \text { to } \\
147.0)\end{array}$ & $\begin{array}{c}140.0(136.0 \text { to } \\
144.0)\end{array}$ & NS \\
\hline Potassium (mEq/l) & 4.1 (3.5 to 4.8$)$ & 4.10 (3.5 to 6.9$)$ & NS & 4.10 (3.6 to 6.9$)$ & 4.1 (3.5 to 4.8$)$ & NS \\
\hline Prothrombin time (s) & $\begin{array}{c}10.7(9.8 \text { to } 11.3), n= \\
71\end{array}$ & $\begin{array}{c}10.4(9.6 \text { to } 11.6), n= \\
68\end{array}$ & $<0.001$ & $10.6 \pm 0.3, n=28$ & $10.4 \pm 0.4, n=40$ & NS \\
\hline
\end{tabular}

Data are expressed as the mean $\pm S D$ or as medians and ranges; $\mathrm{n}$ indicates the number of subjects used to calculate the statistics, and these may vary due to the unavailability of enough plasma to complete the analyses.

NS = not significant.

Table 2 Hormonal status of each subgroup of females

\begin{tabular}{|c|c|c|c|c|c|c|}
\hline Hormone & Fs & FOCs & $\begin{array}{c}P \\
\text { value }\end{array}$ & $\mathrm{FOCA}^{+}$ & $\mathrm{FOCA}^{-}$ & $\begin{array}{c}P \\
\text { value }\end{array}$ \\
\hline Cortisol (ng/ml) & $\begin{array}{c}202.5(75.5 \text { to } 373.1), \mathrm{n} \\
=44\end{array}$ & $\begin{array}{c}334.2(177.0 \text { to } 584.9), \mathrm{n} \\
=32\end{array}$ & $\begin{array}{c}< \\
0.001\end{array}$ & $318.0 \pm 76.6, n=16$ & $349.4 \pm 98.2, n=16$ & NS \\
\hline Estradiol (pg/ml) & $\begin{array}{c}27.7(6.6 \text { to } 172.0), n= \\
42\end{array}$ & $19.7(5.5 \text { to } 77.0)^{a}, n=9$ & NS & $35.1 \pm 30.9, n=4$ & $25.9 \pm 20.7, n=5$ & NS \\
\hline Testosterone (ng/dl) & $49.9 \pm 19.2, n=33$ & $33.9 \pm 14.9, \mathrm{n}=27$ & $\begin{array}{c}< \\
0.001\end{array}$ & $31.4 \pm 7.3, n=13$ & $36.2 \pm 19.3, n=14$ & NS \\
\hline Luteinizing hormone $(\mathrm{mlU} / \mathrm{ml})$ & $6.7(2.6$ to 16.5$), n=44$ & $3.7(0.2$ to 10.4$), n=32$ & $\begin{array}{c}< \\
0.001\end{array}$ & $\begin{array}{c}2.2(0.2 \text { to } 10.4), n= \\
16\end{array}$ & $\begin{array}{c}4.4(0.2 \text { to } 9.6), n= \\
16\end{array}$ & NS \\
\hline $\begin{array}{l}\text { Follicle-stimulating hormone } \\
(\mathrm{mlU} / \mathrm{ml})\end{array}$ & $6.8(2.8$ to 10.7$), n=44$ & $5.6(1.2$ to 20.2$), n=32$ & 0.001 & $\begin{array}{c}4.9(1.5 \text { to } 8.5), n= \\
16\end{array}$ & $\begin{array}{c}4.3(1.2 \text { to } 20.2), n= \\
16\end{array}$ & NS \\
\hline $\begin{array}{l}\text { Thyroid-stimulating hormone } \\
(\mu \mathrm{U} / \mathrm{ml})\end{array}$ & 1.7 (0.7 to 4.7$), n=79$ & $1.9(0.7$ to 10.9$), n=76$ & NS & $\begin{array}{c}1.4(0.7 \text { to } 10.9), n= \\
32\end{array}$ & $\begin{array}{c}2.0(0.8 \text { to } 6.3), n= \\
44\end{array}$ & 0.030 \\
\hline
\end{tabular}

Data are expressed as the mean \pm SD or as medians and ranges; $\mathrm{n}$ indicates the number of subjects used to calculate the statistics, and these may vary due to the unavailability of enough serum to complete the analyses.

an many samples of oral contraceptive users, estradiol was below the detection limit $(5 \mathrm{pg} / \mathrm{ml})$, so they were excluded.

$\mathrm{FOCA}^{+} / \mathrm{FOCA}^{-}=$FOCs further stratified as a function of androgenic $\left(\mathrm{FOCA}^{+}\right)$and non-androgenic $\left(\mathrm{FOCA}^{-}\right)$properties of progestins; FOCs $=$women treated with OCs for at least 3 months; Fs = women who had not used OCs for at least 3 months to ensure a sufficient washout period; NS = not significant; OC = oral contraceptive. 
Table 3 Plasma arginine and plasma methylated arginine

\begin{tabular}{|c|c|c|c|c|c|c|}
\hline Arginine type & Fs, $n=72$ & FOCs, $n=67$ & $\begin{array}{c}P \\
\text { value }\end{array}$ & $\mathrm{FOCA}^{+}, \mathrm{n}=\mathbf{2 8}$ & $\mathrm{FOCA}^{-}, \mathrm{n}=39$ & $\begin{array}{c}P \\
\text { value }\end{array}$ \\
\hline Arginine $(\mu \mathrm{M})$ & $77.4 \pm 15.5$ & $55.7 \pm 13.9$ & $\begin{array}{c}< \\
0.001\end{array}$ & $55.97 \pm 13.86$ & $55.52 \pm 14.04$ & NS \\
\hline Asymmetric dimethylarginine $(\mu \mathrm{M})$ & 0.5 (0.3 to 0.8$)$ & $0.4(0.3$ to 0.7$)$ & $\begin{array}{c}< \\
0.001\end{array}$ & $0.44 \pm 0.13$ & $0.41 \pm 0.11$ & NS \\
\hline Symmetric dimethylarginine $(\mu \mathrm{M})$ & $0.4(0.2$ to 0.7$)$ & $0.4(0.2$ to 0.6$)$ & NS & $0.43 \pm 0.09$ & $0.40 \pm 0.10$ & NS \\
\hline $\begin{array}{l}\text { Asymmetric dimethylarginine/asymmetric } \\
\text { dimethylarginine }\end{array}$ & $1.2(0.7$ to 1.9$)$ & $1.0(0.6$ to 2.4$)$ & $\begin{array}{c}< \\
0.001\end{array}$ & $1.0(0.6$ to 2.0$)$ & 0.9 (0.6 to 2.4$)$ & NS \\
\hline Asymmetric dimethylarginine/arginine & $\begin{array}{l}0.006(0.004 \text { to } \\
0.01)\end{array}$ & $\begin{array}{l}0.007(0.004 \text { to } \\
0.01)\end{array}$ & 0.026 & $\begin{array}{l}0.008(0.004 \text { to } \\
0.01)\end{array}$ & $\begin{array}{l}0.007(0.004 \text { to } \\
0.01)\end{array}$ & NS \\
\hline
\end{tabular}

Data are expressed as the mean \pm SD or as medians and ranges; $n$ indicates the number of samples used to calculate the statistics. $\mathrm{FOCA}^{+} / \mathrm{FOCA}^{-}=\mathrm{FOCs}$ further stratified as a function of androgenic $\left(\mathrm{FOCA}^{+}\right)$and non-androgenic $\left(\mathrm{FOCA}^{-}\right)$properties of progestins; FOCs $=$women treated with OCs for at least 3 months; Fs = women who had not used OCs for at least 3 months to ensure a sufficient washout period; NS $=$ not significant; OC $=$ oral contraceptive.

parameters. Malonyldialdehyde, an index of lipid peroxidation, was not significantly different among the groups (Table 4), whereas total bilirubin was lower in FOCs than in Fs (Table 1). Among plasma thiols, cysteine was significantly lower in FOCs than in Fs, while homocysteine, glutathione, cysteinglycine, glucylcysteine and taurine, an endogenous inhibitor of hypochlorous acid [27], were not different (Table 4). Moreover, none of the above parameters was influenced by the androgenic properties of progestin (Table 4).

\section{Global DNA methylation}

Global DNA methylation was measured in white blood cells and expressed as percentage methylcytosine normalized to white blood cell number. Methylation was significantly higher in FOCs than in Fs (Figure 1), but the androgenic properties of progestin did not affect this parameter (data not shown).

\section{Expression and activities of estrogen and androgen receptors in MDMs obtained from different female populations}

MDMs expressed androgen receptors, estrogen receptor $\alpha$, and estrogen receptor $\beta$ (Figure 2), with the $\beta$ isoform being the most highly expressed, as indicated comparing the estrogen receptor $\beta$ band with the band obtained by loading 5 ng of recombinant proteins. Consequently, MDMs presented a low estrogen receptor $\alpha /$ estrogen receptor $\beta$ ratio. The use of OCs had a considerable impact on estrogen receptor levels: they increased estrogen receptor $\alpha$ approximately fivefold and decreased estrogen receptor $\beta$ approximately 0.5 -fold in comparison with Fs. This effect led to a significant increase in the estrogen receptor $\alpha /$ estrogen receptor $\beta$ ratio in MDMs derived from FOCs compared to Fs (Figure 2). When the FOCs were stratified according to the androgenic and non-androgenic properties of progestin, we observed that estrogen receptor $\alpha$ and estrogen receptor $\beta$ levels were at least twice as high in $\mathrm{FOCA}^{+}$ than in FOCA ${ }^{-}$. Consequently, the $\alpha / \beta$ ratio was significantly higher in $\mathrm{FOCA}^{-}$than in $\mathrm{FOCA}^{+}$(Figure 2). The result obtained in FOCs prompted us to investigate whether the altered levels of estrogen receptor isoforms were paralleled by differences in their activation statuses by measuring the phosphorylation of estrogen receptor $\alpha$ Ser118 and the activation of p38 as a measure of estrogen receptor $\beta$ activity $[28,29]$. The phosphorylated form of estrogen receptor $\alpha$ was undetectable in our

Table 4 Plasma lipid peroxidation, thiols and taurine

\begin{tabular}{|c|c|c|c|c|c|c|}
\hline Type & Fs, $n=72$ & FOCs, $n=67$ & $P$ value & $\mathrm{FOCA}^{+}, \mathrm{n}=\mathbf{2 8}$ & $\mathrm{FOCA}^{-}, \mathrm{n}=39$ & $P$ value \\
\hline Malonyldialdehyde $(\mu \mathrm{M})$ & $4.2 \pm 1.9, n=69$ & $4.1 \pm 1.7, n=66$ & NS & $3.7(1.3$ to 8.6$), n=27$ & $3.9(0.9$ to 8.6$), n=39$ & NS \\
\hline Homocysteine $(\mu \mathrm{M})$ & 8.7 (4.0 to 41.1) & 8.3 (4.3 to 16.7 ) & NS & $8.3 \pm 2.9$ & $8.9 \pm 2.9$ & NS \\
\hline Cysteine $(\mu \mathrm{M})$ & 195.6 (118.9 to 350.7$)$ & 176.6 (115.8 to 318.4$)$ & 0.003 & $181.5 \pm 39.8$ & $186.6 \pm 45.4$ & NS \\
\hline Cysteinglycine $(\mu \mathrm{M})$ & 18.7 (7.6 to 33.6) & 19.5 (7.4 to 38.8$)$ & NS & 20.6 (11.4 to 38.8$)$ & 18.9 (7.4 to 33.0$)$ & NS \\
\hline Glucylcysteine $(\mu \mathrm{M})$ & $4.5 \pm 1.0$ & $4.5 \pm 0.9$ & NS & $4.4 \pm 1.0$ & $4.5 \pm 0.9$ & NS \\
\hline Glutathione $(\mu \mathrm{M})$ & 7.4 (2.7 to 14.8$)$ & 8.0 (3.9 to 14.9) & NS & $8.0 \pm 2.4$ & $8.2 \pm 2.0$ & NS \\
\hline Taurine $(\mu \mathrm{M})$ & 64.1 (31.7 to 202.7) & 59.6 (27.3 to 158.9$)$ & NS & $60.9(27.3$ to 146.8$)$ & 59.4 (36.3 to 158.9$)$ & NS \\
\hline
\end{tabular}

Data are expressed as the mean \pm SD or as medians and ranges; $n$ indicates the number of samples used to calculate the statistics.

$\mathrm{FOCA}^{+} / \mathrm{FOCA}^{-}=$FOCs further stratified as a function of androgenic $\left(\mathrm{FOCA}^{+}\right)$and non-androgenic $\left(\mathrm{FOCA}^{-}\right)$properties of progestins; $\mathrm{FOCS}=$ women treated with OCs for at least 3 months; Fs = women who had not used OCs for at least 3 months to ensure a sufficient washout period; NS = not significant; OC = oral contraceptive. 


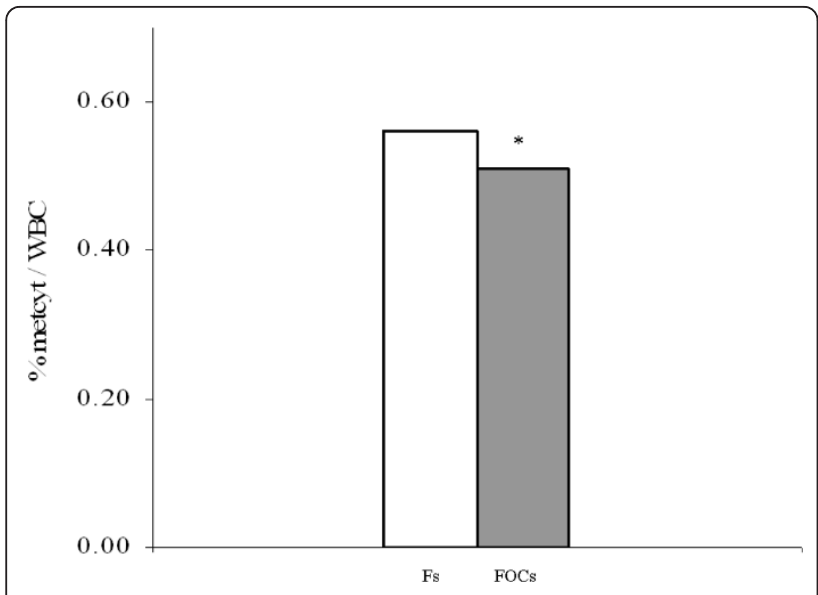

Figure 1 Global DNA methylation in the two female populations. Data are expressed as the medians of $72 \mathrm{Fs}$ (white bar) and 67 FOCs (grey bar); ${ }^{*} P=0.033$. FOCs $=$ women treated with OCs for at least 3 months; Fs = women who had not used OCs for at least 3 months to ensure a sufficient washout period; OC $=$ oral contraceptive.

samples, indicating that this receptor was inactive, whereas estrogen receptor $\alpha$ phosphorylation was evident in MCF-7 cells (used as a positive control). The phosphorylation of $\mathrm{p} 38$, and thus estrogen receptor $\beta$ activation, was decreased in MDMs obtained from FOCs compared to Fs, indicating that OCs not only decreased the level but also the activity of estrogen receptor $\beta$ (Figure 3). Finally, the levels of androgen receptors were not changed by the use of OCs, indicating that OCs have a specific impact on estrogen receptor levels and activities (Figure 2).

\section{Basal and lipopolysaccharide-induced release of TNF $\alpha$ from MDMs obtained from different female populations}

Estrogens influence the inflammatory response through several mechanisms, including cytokine suppression [30]. This prompted us to evaluate if modifications in serum estrogen levels and in estrogen receptor expression were associated with changes in basal and lipopolysaccharide-induced release of TNF $\alpha$. Despite the great variability in the basal release of TNF $\alpha$, we found that basal cytokine release was consistently significantly higher in FOCs than in the Fs (Table 5). The release of TNF $\alpha$ was increased by lipopolysaccharide in all groups and was significantly higher in Fs than in FOCs. The androgenic properties of progestin did not influence release of TNF $\alpha$.

\section{Discussion}

OCs modify the pituitary-ovarian axis (decreased luteinizing hormone, follicle-stimulating hormone, testosterone and estradiol), which is characteristic of the inhibition of ovulation [31,32]. The pituitary-adrenal axis (increased cortisol) is also altered by OCs and this results is in line with previous findings [6,33].

Thyroid-stimulating hormone levels were not significantly different between Fs and FOCs. However, when $\mathrm{FOCA}^{-}$and $\mathrm{FOCA}^{+}$were considered, thyroid-stimulating hormone was elevated in FOCA ${ }^{-}$. Our results are in line with those observed by Wiegratz et al. , who reported that thyroid-stimulating hormone was significantly increased with the use of OCs containing a non-androgenic progestin [34].

We also confirmed that OCs induced variations in hematological and biochemical parameters, such as lymphocyte count, prothrombin time, total iron binding capacity of transferrin, C-reactive protein, and lipids [10,23-25]. Some parameters were influenced by the androgenic properties of progestin: high-density lipoproteins were higher in $\mathrm{FOCA}^{-}$, in accord with the findings of van Rooijen et al. [26], while hemoglobin, white blood cell count, calcium, percentage saturation and $\gamma-$ glutamyl transpeptidase were lower in $\mathrm{FOCA}^{-}$, as previously reported [35].

The primary novelty of our study is the fact that OCs modified estrogen receptor $\alpha$ and estrogen receptor $\beta$ levels, and estrogen receptor $\beta$ activity, while leaving androgen receptor expression unchanged. In particular, estrogen receptor $\alpha$ was markedly increased, whereas estrogen receptor $\beta$ was largely decreased; consequently, the ratio of $\alpha / \beta$ was greatly altered. The variations in estrogen receptor levels were associated with changes in the activation status only of estrogen receptor $\beta$. In fact, estrogen receptor $\alpha$ activity was undetectable in all groups, indicating that this receptor is not active in basal conditions. Conversely, p38 phosphorylation, an important step in estrogen receptor $\beta$ signal transduction [4], was significantly lower in FOCs than in Fs. Importantly, the androgenic and non-androgenic properties of progestin affected only the expression of the $\beta$ isoform.

OC-induced modification of hormonal levels and the estrogen receptor $\alpha /$ estrogen receptor $\beta$ ratio was accompanied by a significant increase in basal release of TNF $\alpha$. When the ratio between the two estrogen receptors was the highest, we observed the greatest release of TNF $\alpha$. Interestingly, these data strongly suggest that MDMs retain a selective 'memory' of their in vivo environment. They also suggest that FOCs who also had high C-reactive protein levels are more prone to inflammation. In this context, it is important to remember that FOCs had higher cortisol levels, which could impact release of TNF $\alpha$. It should be noted that lipopolysaccharide-induced release of TNF $\alpha$ was higher in Fs and that Fs had lower cortisol and higher estradiol. The influence of sex hormones on release of TNF $\alpha$ has been suggested by Amory et al. [36], and recently a direct 


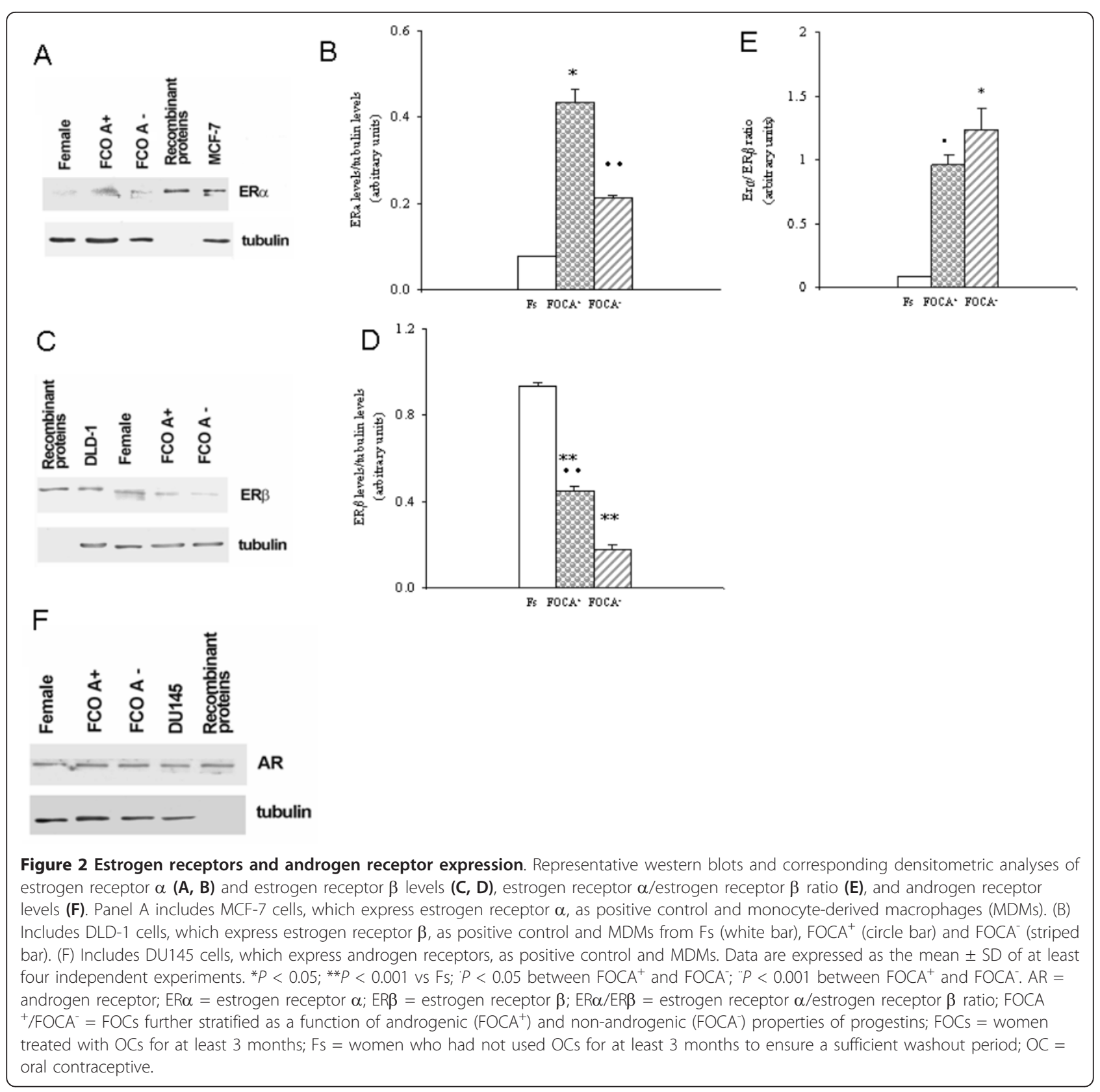

correlation between estrogen receptor $\alpha$ expression and the suppression of lipopolysaccharide-induced CXCL8 secretion has been shown [20], but because estrogen receptor $\alpha$ was not active in our samples, we believe that the cortisol increase is of some importance. These results are in line with the OC-induced modifications of human T lymphocytes [37]. Notably, the release of cytokines by macrophages and monocytes appears to be an endocrine phenomenon. Generally, when estrogen is elevated, resting peripheral blood monocytes release less interleukin-1 $\beta$ and TNF $\alpha[38,39]$. Moreover, monocytes obtained from surgically postmenopausal women release a higher amount of cytokines, and importantly, the administration of estrogen restores premenopausal cytokine levels [40]. When peripheral blood mononuclear cells are stimulated with lipopolysaccharide, mRNA expression and secretion of interleukin- $1 \beta$ and TNF $\alpha$ are increased in the luteal phase compared with the follicular phase [41].

Another important result of this study is the fact that OCs ameliorate endothelial function, as indicated by decreased asymmetric dimethylarginine. This marker of endothelial function is also an independent predictor of cardiovascular events and mortality [12]. Although the 


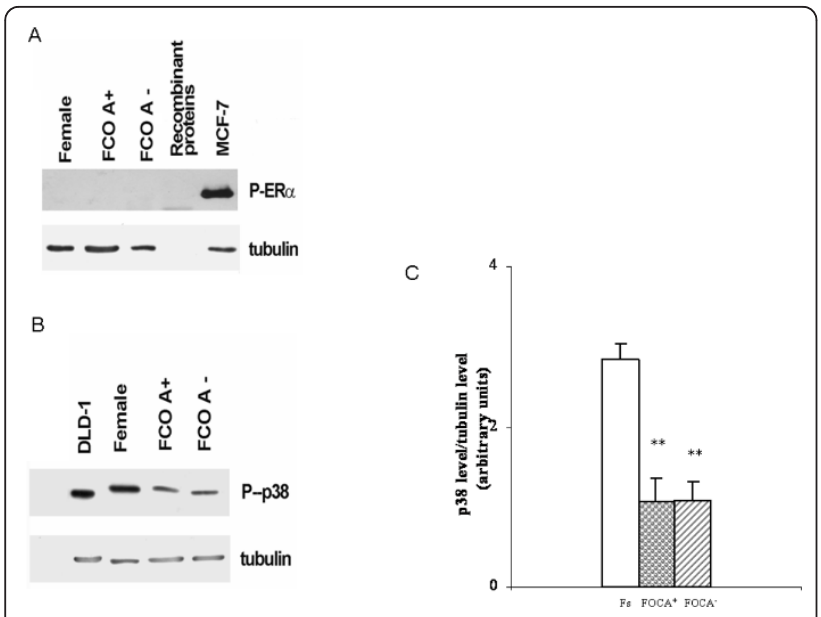

Figure 3 Activation status of estrogen receptors. Representative western blot for estrogen receptor $\alpha$ phosphorylation (A) and representative western blot with corresponding densitometric analysis of estrogen receptor $\beta$ activity (measured as p38 phosphorylation) (B, C) in estrogen receptor $\alpha$-expressing MCF-7 and estrogen receptor $\beta$-expressing DLD-1 cell lines stimulated with $10 \mathrm{nM}$ estradiol $(1 \mathrm{~h})$ and in monocyte-derived macrophages (MDMs) from Fs (white bar), FOCA (circle bar) and FOCA' (striped bar). Data are expressed as the mean \pm SD of at least four independent experiments. ${ }^{* *} P<0.001$ vs Fs. FOCA ${ }^{+} / F O C A^{-}=$FOCs further stratified as a function of androgenic $\left(\mathrm{FOCA}^{+}\right)$and nonandrogenic $\left(\mathrm{FOCA}^{-}\right)$properties of progestins; $\mathrm{FOCs}=$ women treated with OCs for at least 3 months; Fs = women who had not used OCs for at least 3 months to ensure a sufficient washout period; OC $=$ oral contraceptive.

absolute reduction of this endogenous inhibitor of nitric oxide synthase was small, the biological variation in the plasma asymmetric dimethylarginine/arginine ratio is also very low and even a slight increase in the asymmetric dimethylarginine/arginine ratio is associated with an elevated risk of acute coronary events [12]. The reduction in the asymmetric dimethylarginine/arginine ratio is in line with the results of Valtonen et al. [11]. Notably, the ratio increase was mainly sustained by a decrease in arginine. The decrease in arginine is not a universal finding [11], and the reasons for this discrepancy are not well understood, but a decrease in arginine has been reported after oral hormonal replacement therapy [42].

The reduction in total DNA methylation in FOCs was small but significant. Variations in DNA methylation imply heritable epigenetic changes in gene function [42]. Notably, global hypomethylation predisposes to agerelated chronic diseases, including atherosclerosis $[43,44]$. The global hypomethylation of DNA and reduction of asymmetric dimethylarginine occurred in the presence of a significant variation of homocysteine; previously it has been shown that folate does not differ between OC users and non-users [45], suggesting that the decreases in asymmetric dimethylarginine and DNA methylation are not attributable to a decrease in folate. In our opinion, the low levels of cysteine and DNA methylation suggest a slowdown during the demethylation and trans-sulfuration phases of the methionine cycle, which can reasonably produce a decrease in asymmetric dimethylarginine, although it is not possible to exclude other mechanisms.

When the study population was stratified for OC use, the results obtained were mainly in line with results in the literature, indicating that the sample number was sufficient to discriminate differences. Indeed, the further stratification into $\mathrm{FOCA}^{+}$and $\mathrm{FOCA}^{-}$groups might have influenced the statistical power, and therefore, further differences due to the activity of progestin may not have been detected. Some information was self-reported data, which contains several potential sources of bias. Another caveat is the lack of randomization and the fact that the study enrolled women who were treated with several OCs that contained different progestin-based molecules with androgenic and non-androgenic properties. However, the current study specifically focused on evaluating factors related to MDM function in a real population and whether function was affected by OC treatment, as well as investigating whether OCs could also produce alterations in cell functions, thereby affecting the pharmacodynamics of the drugs under examination.

Table 5 Release of tumor necrosis factor $\alpha$ in monocyte-derived macrophages (MDMs) obtained from each subgroup of females

\begin{tabular}{|c|c|c|c|}
\hline Subgroup & Unstimulated (ng/ml) & Lipopolysaccharide (\% increase) & $P$ value \\
\hline Fs, $n=76$ & 67.4 (12.1 to 971.8$)$ & 2786.7 (323.6 to 29272.3) & $<0.001^{a}$ \\
\hline FOCs, $n=68$ & $93.8(14.7$ to 702.5$)$ & $1694.3(476.6$ to 15386.7$)$ & $<0.001^{\mathrm{a}} ;<0.02^{*}$ \\
\hline $\mathrm{FOCA}^{+}, \mathrm{n}=33$ & 90.5 (14.7 to 693.7$)$ & 1597.9 (507.3 to 10314.1$)$ & $<0.001^{\mathrm{a}}$ \\
\hline $\mathrm{FOCA}^{-}, \mathrm{n}=35$ & 88.6 (15.8 to 702.5$)$ & 1977.8 (476.6 to 15386.7 ) & $<0.001^{a}$ \\
\hline
\end{tabular}

Data are medians and ranges; $n$ indicates the number of samples used to calculate the statistics.

${ }^{a}$ Indicates the $P$ value between unstimulated and stimulated MDMs.

${ }^{*} P$ value between FOCs and Fs.

$\mathrm{FOCA}^{+} / \mathrm{FOCA}^{-}=$FOCs further stratified as a function of androgenic $\left(\mathrm{FOCA}^{+}\right)$and non-androgenic $\left(\mathrm{FOCA}^{-}\right)$properties of progestins; FOCs $=$women treated with OCs for at least 3 months; Fs = women who had not used OCs for at least 3 months to ensure a sufficient washout period; OC = oral contraceptive. 


\section{Conclusions}

In summary, these findings suggest that contraceptive therapy impacts the function of cells (MDMs) that play crucial roles in immunity and atherosclerosis $[17,18]$, modifying the release of TNF $\alpha$. Notably, the androgenic properties of progestin alter several properties of MDMs. OCs modify total DNA methylation, and this epigenetic change occurs independently of the androgenic properties of progestin. Considering that the preparation of MDMs from monocytes requires 10 days, it is also conceivable that the modifications induced by OCs are long lasting. At the moment, it is not known whether these effects are reversible.

Intuitively, these modifications could have a relevant impact on pharmacological targets. The impact may be different according to the androgenic properties of progestin. This implies that a single type of OC should be used during a single trial, because the type of OC used could influence the results of the designed study. We are also confident that bringing attention to this problem could help to improve drug therapy in women, who currently experience almost twice the number of adverse events as men [3].

\section{Methods}

\section{Ethics statement}

The local ethical committee of Azienda OspedalieroUniversitaria of Sassari approved this study. Informed consent taking and blood sampling were performed at a voluntary blood donation session. Women willing to donate blood were asked to donate during the follicular phase of their menstrual cycle and informed that an aliquot of blood would be kept for the study. Blood chemistry tests were performed as a scheduled service for blood donors.

\section{Subjects}

A total of 162 healthy adult women (85 non-users of OCs and 77 OC users) with regular menstrual cycles (28 days) aged 27 years (range 18 to 39 ) were enrolled during the period July 2007 to November 2010 at the Servizio di Diagnosi e Cura di Endocrinologia, Azienda Ospedaliero-Universitaria, Sassari. Weight and height were used to calculate body mass index. Women were defined as healthy after a physical examination and after blood chemistry analysis.

Women were free of kidney, liver, heart, and endocrine diseases and infective diseases for at least 2 months prior to the study and did not use chronic pharmaceutical treatments, with the exception of OCs. The population was stratified into two groups: Fs and FOCs, as defined earlier. This was due to the fact some women may need to change the type of $\mathrm{OC}$ in use to optimize the anticonceptional therapy. FOCs were further stratified as a function of the androgenic $\left(\mathrm{FOCA}^{+}\right)$and nonandrogenic $\left(\mathrm{FOCA}^{-}\right)$properties of the progestins. OCs belonged to the new generation and contained ethinylestradiol, for which the most representative dose was 20 $\mu \mathrm{g}(\mathrm{n}=42)$. The most used progestin dose was $3 \mathrm{mg}$ ( $\mathrm{n}$ =32); the androgenic progestins used were gestodene (the most frequently used), desogestrel, and levonorgestrel, whereas drospirenone and clormadinone have no androgenic properties [22], with drospirenone used most frequently.

\section{Biochemical and hematological examinations}

Laboratory assessments of several biomarkers were conducted on $10 \mathrm{ml}$ of fasting blood samples $(8.00 \mathrm{am}$ and $10.00 \mathrm{am}$ ) obtained from the antecubital vein of women in the follicular phase of their menstrual cycle ( 1 to 10 days). Blood was put in tubes with the appropriate anticoagulant (sodium citrate for coagulation, silicone coating for serum determinations and potassium-ethylenediaminetetra-acetic acid (EDTA) for all the other assessments). Plasma was aliquoted, stored at $-80^{\circ} \mathrm{C}$ and used within 1 month to measure cysteine, homocysteine, glutathione, cysteinglycine, glucylcysteine, arginine, asymmetric dimethylarginine and symmetric dimethylarginine according to the method of Zinellu et al. [46-48] and to measure malonyldialdehyde according to the method of Esterbauer and Cheeseman [49], with slight modifications. Other plasma aliquots were immediately used for measuring fasting glucose, total cholesterol, low-density lipoproteins, high-density lipoproteins, triglycerides, creatinine, uric acid, urea, total bilirubin, aspartate aminotransferase, alanine aminotransferase, $\gamma$ glutamyl transpeptidase, alkaline phosphatase, calcium, sodium, potassium, sideremia, ferritin, C-reactive protein, prothrombin time, total iron binding capacity of transferrin and percentage saturation using standard laboratory procedures. Full blood aliquots were used to measure red cell count, leucocyte formula, platelet count, hemoglobin, hematocrit, and mean corpuscular volume. White blood cells were also used to determine the degree of global DNA methylation as previously described [50]. Aliquots of serum were also prepared to measure hormones. In particular, cortisol (Cortisol RIA CT, Chematil S.r.L., Angri, Italy), thyroid-stimulating hormone (VITROS TSH, Ortho-Clinical Diagnostics Johnson \& Johnson, Roma, Italy), estradiol (Estradiol MAIA, Adaltis Italia S.p.A., Bologna, Italy) and testosterone (Testosterone RIA CT, RADIM S.p.A, Pomezia, Italy) were measured by RIA using commercial kits, while luteinizing hormone (LH IRMA kit, Immunotech a.s., Milano, Italy) and follicle-stimulating hormone (FSH IRMA kit, Immunotech a.s.) were detected by 
IRMA using commercial kits. Intra-assay and interassay coefficients of variation were less than $2.5 \%$.

\section{Human monocyte isolation and MDM differentiation}

An aliquot of blood taken from healthy volunteers (30 $\mathrm{ml}$ ) was used for the isolation of monocytes. Briefly, blood was diluted with phosphate-buffered saline $(\mathrm{pH}$ 7.4 ), layered over a histopaque (density $1.077 \mathrm{~g} / \mathrm{cm}^{3}$, Sigma Aldrich, Milano, Italy) gradient solution, centrifuged ( $400 \mathrm{~g}, 25 \mathrm{~min}$, room temperature (RT)) and recovered by thin suction at the interface. The mononuclear cell layer was washed twice by centrifuging with phosphate buffer (200 $g, 10 \mathrm{~min}, \mathrm{RT})$ and then resuspended in RPMI 1640 medium (Invitrogen, S. Giuliano Milanese, Italy) supplemented with $20 \%$ heat-inactivated fetal bovine serum (Invitrogen, S. Giuliano Milanese, Italy), 2 mM glutamine, 10 mM 4-(2-hydroxyethyl)-1-piperazineethanesulfonic acid (HEPES, Sigma Aldrich, Milano, Italy), and $1 \%$ antibiotic/antimycotic (Invitrogen, S. Giuliano Milanese, Italy). Purified monocytes were obtained by adhesion; non-adherent cells (mainly lymphocytes) were removed by gentle washes with phosphate buffer. MDMs were prepared from monocytes cultured for 8 to 10 days in a $5 \% \mathrm{CO}_{2}$ incubator at $37^{\circ} \mathrm{C}$ in RPMI 1640 medium containing $20 \%$ fetal bovine serum, 2 mM glutamine, $10 \mathrm{mM}$ HEPES and antibiotics/antimycotics; medium was changed every 2 to 3 days. MDMs were prepared and characterized as described [51].

\section{Expression and activation status of estrogen receptor $\alpha$, estrogen receptor $\beta$ and androgen receptor in MDMs derived from different female populations}

An aliquot of MDMs was lysed, seeded in six-well plates, washed twice with ice-cold phosphate-buffered saline (PBS) and scraped in lysis buffer $(20 \mathrm{mM}$ Tris- $\mathrm{HCl}(\mathrm{pH}$ 7.5), $150 \mathrm{mM} \mathrm{NaCl}, 1 \mathrm{mM} \mathrm{Na} 2$ EDTA, $1 \mathrm{mM}$ ethylene glycol tetra-acetic acid (EGTA), 1\% Triton X, $2.5 \mathrm{mM}$ sodium pyrophosphate, $1 \mathrm{mM} \beta$-glycerophosphate, $1 \mathrm{mM}$ $\mathrm{Na}_{3} \mathrm{VO}_{4}, 1 \mu \mathrm{g} / \mathrm{ml}$ leupeptin and $1 \mathrm{mM}$ phenylmethanesulfonylfluoride (PMSF), Sigma Aldrich, Milano, Italy). The lysate was centrifuged $\left(13,000 \mathrm{~g} ; 10 \mathrm{~min}, 4^{\circ} \mathrm{C}\right)$; the supernatants obtained were collected and stored at $-80^{\circ} \mathrm{C}$ until western blot analyses for estrogen receptor $\alpha$, estrogen receptor $\beta$ and androgen receptor [29]. To measure estrogen receptor $\alpha$ and estrogen receptor $\beta$, electrophoreses were performed in the presence of $5 \mathrm{ng}$ of recombinant estrogen receptor $\alpha$ and estrogen receptor $\beta$.

The activation states of estrogen receptors were evaluated by analyzing the phosphorylation of Ser118 of estrogen receptor $\alpha$ and the phosphorylation of p38 for estrogen receptor $\beta$, according to [4]. Protein concentration was determined with the Pierce BCA protein assay kit (Thermo Scientific, Celbio SPA, Pero, Italy). Moreover, a standard curve of recombinant proteins showed that the band intensity was proportional to the protein quantity. Antibody reaction was visualized with chemiluminescence Western Blotting Detection Reagent (Amersham Biosciences, Little Chalfont, UK). Densitometric analyses were performed with ImageJ software for Windows http://rsbweb.nih.gov/ij/.

\section{Spontaneous and lipopolysaccharide-induced release of TNF $\alpha$ from MDMs derived from different female populations}

MDMs $\left(1.4 \times 10^{4}\right)$ were incubated for $24 \mathrm{~h}$ in the absence or presence of $100 \mathrm{ng} / \mathrm{ml}$ lipopolysaccharide (Sigma Aldrich, Milano, Italia), a component of Gramnegative bacterial cell walls, that binds to Toll-like receptor 4 [52]. Supernatants were then collected and stored at $-80^{\circ} \mathrm{C}$ and used to measure TNF $\alpha$ using a commercial ELISA kit (human TNFa/TNFSF1A DuoSet ELISA kit, R\&D Systems, Milano, Italy) following the manufacturer's instructions.

\section{Statistical analysis}

Statistical analysis was performed by comparing Fs versus FOCs and $\mathrm{FOCA}^{+}$versus FOCA'. Continuous parametric variables were analyzed using the Student's t test. Non-parametric variables were compared between groups by the Mann-Whitney rank test. For all tests, a $P$ value $\leq 0.05$ was considered statistically significant.

\section{Acknowledgements \\ This study was financially supported by grants from the Italian Health Ministry 'Ricerca Finalizzata 2007' and LR 7/2007 Progetti di ricerca di base- Bando 2007. IC is supported by an INBB scholarship and a research grant funded by Fondazione Banco di Sardegna. AZ is supported by 'Ricerca cofinanziata Programma Operativo FSE Sardegna 2007-2013-L.R.7/2007- Promozione della ricerca scientifica e dell'innovazione tecnologica in Sardegna'. The authors thank Mrs Mary Forrest for English revision of the manuscript.}

\section{Author details}

${ }^{1}$ National Laboratory of Sex-Gender Medicine of the National Institute of Biostructures and Biosystems, Osilo, Italy. ${ }^{2}$ Centre of Excellence for Biotechnology Development and Biodiversity Research, University of Sassari, Sassari, Italy. ${ }^{3}$ Porto Conte Ricerche Srl, Tramariglio, Alghero, Sassari, Italy. ${ }^{4}$ Department of Biomedical Sciences and Centre of Excellence for Biotechnology Development and Biodiversity Research, University of Sassari, Sassari, Italy. ${ }^{5}$ Laboratory Department, SS Annunziata Hospital, Sassari, Italy. ${ }^{6}$ Department of Biology, University Roma Tre, Rome, Italy. ${ }^{7}$ Department of Internal Medicine, Spedali Riuniti, Pistoia, Italy. ${ }^{8}$ SC Diabetologia Aziendale ASL 2 Olbia, Hospital San Giovanni di Dio, Olbia, Italy. ${ }^{9}$ Servizio di Diagnosi e Cura di Endocrinologia, Azienda Ospedaliero-Universitaria, Sassari, Italy.

${ }^{10}$ IRCCS San Raffaele Pisana, Rome, Italy.

\section{Authors' contributions}

FF, GT, MM, GR and MP conceived and designed the experiments. IC, MS, $A Z$, LR, CC, PB, MP and MM performed the experiments. GS, CC, IC and MS analyzed the data. IC, FF and MM wrote the paper. All authors read and approved the final manuscript.

\section{Competing interests}

The authors have no conflict of interest that could be perceived as prejudicing the impartiality of the research reported. 
Received: 24 October 2011 Accepted: 27 January 2012

Published: 27 January 2012

\section{References}

1. US Food and Drug Administration: Investigational New Drug Applications and New Drug Applications. Rules and Regulations. Federal Register. In Gender-Specific Medicine FR 6854. Volume 63. Rockville, MD, US FDA; 1998.

2. Cain J, Lowell J, Thorndyke L, Localio AR: Contraceptive requirements for clinical research. Obstet Gynecol 2000, 95:861-866.

3. Franconi F, Brunelleschi S, Steardo L, Cuomo V: Gender differences in drug responses. Pharmacol Res 2007, 55:81-95.

4. Ascenzi P, Bocedi A, Marino M: Structure-function relationship of estrogen receptor alpha and beta: impact on human health. Mol Aspects Med 2006, 27:299-402.

5. Willis SA, Kuehl TJ, Spiekerman AM, Sulak PJ: Greater inhibition of the pituitary-ovarian axis in oral contraceptive regimens with a shortened hormone-free interval. Contraception 2006, 74:100-103.

6. Kirschbaum C, Kudielka BM, Gaab J, Schommer NC, Hellhammer DH: Impact of gender, menstrual cycle phase, and oral contraceptives on the activity of the hypothalamus-pituitary-adrenal axis. Psychosom Med 1999, 61:154-162.

7. Skouby SO, Andersen O, Saurbrey N, Kuhl C: Oral contraception and insulin sensitivity in vivo assessment in normal women and women with previous gestational diabetes. J Clin Endocrinol Metab 1987, 64:519-523.

8. Petersen KR, Christiansen E, Madsbad S, Skouby SO, Andersen LF, Jespersen J: Metabolic and fibrinolytic response to changed insulin sensitivity in users of oral contraceptives. Contraception 1999, 60:337-344

9. Wiegratz I, Kuhl H: Progestogen therapies: differences in clinical effects? Trends Endocrinol Metab 2004, 15:277-285.

10. Haarala A, Eklund C, Pessi T, Lehtimaki T, Huupponen R, Jula A, Viikari J, Raitakari O, Hurme M: Use of combined oral contraceptives alters metabolic determinants and genetic regulation of C-reactive protein. The Cardiovascular Risk in Young Finns Study. Scand J Clin Lab Invest 2009, 69:168-174

11. Valtonen P, Punnonen K, Saarelainen H, Heiskanen N, Raitakari OT, Juonala M, Viikari JS, Alfthan G, Kahonen M, Laaksonen R, Lyyra-Laitinen T, Laitinen $T$, Heinonen S: ADMA concentration changes across the menstrual cycle and during oral contraceptive use: the Cardiovascular Risk in Young Finns Study. Eur J Endocrinol 2010, 162:259-265.

12. Blackwell S: The biochemistry, measurement and current clinical significance of asymmetric dimethylarginine. Ann Clin Biochem 47:17-28.

13. Vessey M, Mant D, Smith A, Yeates D: Oral contraceptives and venous thromboembolism: findings in a large prospective study. Br Med J (Clin Res Ed) 1986, 292:526.

14. Spitzer WO, Lewis MA, Heinemann LA, Thorogood M, MacRae KD: Third generation oral contraceptives and risk of venous thromboembolic disorders: an international case-control study. Transnational Research Group on Oral Contraceptives and the Health of Young Women. BMJ 1996, 312:83-88

15. Langlois MR, Rietzschel ER, De Buyzere ML, De Bacquer D, Bekaert S, Blaton $\mathrm{V}$, De Backer GG, Gillebert TC: Femoral plaques confound the association of circulating oxidized low-density lipoprotein with carotid atherosclerosis in a general population aged 35 to 55 years: the Asklepios Study. Arterioscler Thromb Vasc Biol 2008, 28:1563-1568.

16. Shufelt $\mathrm{CL}$, Bairey Merz CN: Contraceptive hormone use and cardiovascular disease. J Am Coll Cardiol 2009, 53:221-231.

17. Masuda J, Ross R: Atherogenesis during low level hypercholesterolemia in the nonhuman primate. I. Fatty streak formation. Arteriosclerosis 1990, 10:164-177.

18. Parihar A, Eubank TD, Doseff Al: Monocytes and macrophages regulate immunity through dynamic networks of survival and cell death. J Innate Immun 2:204-215.

19. Gordon S, Taylor PR: Monocyte and macrophage heterogeneity. Nat Rev Immunol 2005, 5:953-964

20. Murphy AJ, Guyre PM, Wira CR, Pioli PA: Estradiol regulates expression of estrogen receptor ERalpha46 in human macrophages. PLoS One 2009, 4 e5539.

21. Cerel-Suhl SL, Yeager BF: Update on oral contraceptive pills. Am Fam Physician 1999, 60:2073-2084.

22. Sweetman S: Martindale: The Complete Drug Reference. 34 edition. London, UK: Pharmaceutical Press; 2005
23. Kamyab S, Kamyab SD: Variations in serum iron and total iron binding capacity with the time of intake of combined oral contraceptives. Clin Chim Acta 1976, 66:439-452.

24. Rotteveel RC, Roozendaal KJ, Eijsman L, Hemker HC: The influence of ora contraceptives on the time-integral of thrombin generation (thrombin potential). Thromb Haemost 1993, 70:959-962.

25. Berenson $A B$, Rahman M, Wilkinson G: Effect of injectable and oral contraceptives on serum lipids. Obstet Gynecol 2009, 114:786-794.

26. van Rooijen M, von Schoultz B, Silveira A, Hamsten A, Bremme K: Different effects of oral contraceptives containing levonorgestrel or desogestrel on plasma lipoproteins and coagulation factor VII. Am J Obstet Gynecol 2002, 186:44-48.

27. Franconi F, Di Leo MA, Bennardini F, Ghirlanda G: Is taurine beneficial in reducing risk factors for diabetes mellitus? Neurochem Res 2004, 29:143-150.

28. Acconcia F, Totta P, Ogawa S, Cardillo I, Inoue S, Leone S, Trentalance A Muramatsu M, Marino M: Survival versus apoptotic 17beta-estradiol effect: role of ER alpha and ER beta activated non-genomic signaling. J Cell Physiol 2005, 203:193-201

29. Galluzzo P, Rastelli C, Bulzomi P, Acconcia F, Pallottini V, Marino M: 17betaEstradiol regulates the first steps of skeletal muscle cell differentiation via ER-alpha-mediated signals. Am J Physiol Cell Physiol 2009, 297 : C1249-1262.

30. Chakrabarti S, Lekontseva O, Davidge ST: Estrogen is a modulator of vascular inflammation. IUBMB Life 2008, 60:376-382.

31. Pincus $\mathrm{G}$ : The action of hormonal steroids on the hypothalamo-pituitaryovarian axis. Arch Anat Microsc Morphol Exp 1967, 56:475-485.

32. Poindexter AN, Dildy GA, Brody SA, Snabes MC, Brodyand SA: The effects of a long-acting progestin on the hypothalamic-pituitary-ovarian axis in women with normal menstrual cycles. Contraception 1993, 48:37-45.

33. Liening SH, Stanton SJ, Saini EK, Schultheiss OC: Salivary testosterone, cortisol, and progesterone: two-week stability, interhormone correlations, and effects of time of day, menstrual cycle, and oral contraceptive use on steroid hormone levels. Physiol Behav 99:8-16.

34. Wiegratz I, Kutschera E, Lee JH, Moore C, Mellinger U, Winkler UH, Kuhl H: Effect of four different oral contraceptives on various sex hormones and serum-binding globulins. Contraception 2003, 67:25-32.

35. Straus B, Calic-runje R, Cepelak I: Influence of contraceptives on gamma glutamyltransferase activity. Acta Pharm Jugos/ 1982, 32:191-195.

36. Amory JH, Lawler R, Hitti J: Increased tumor necrosis factor-alpha in whole blood during the luteal phase of ovulatory cycles. J Reprod Med 2004, 49:678-682

37. Prakash M, Kapembwa MS, Gotch F, Patterson S: Oral contraceptive use induces upregulation of the CCR5 chemokine receptor on CD4(+) T cells in the cervical epithelium of healthy women. J Reprod Immunol 2002, 54:117-131.

38. Polan ML, Kuo A, Loukides J, Bottomly K: Cultured human luteal peripheral monocytes secrete increased levels of interleukin-1. J Clin Endocrinol Metab 1990, 70:480-484.

39. Cannon JG, Dinarello CA: Increased plasma interleukin-1 activity in women after ovulation. Science 1985, 227:1247-1249.

40. Pacifici R, Carano A, Santoro SA, Rifas L, Jeffrey JJ, Malone JD, McCracken R, Avioli LV: Bone matrix constituents stimulate interleukin-1 release from human blood mononuclear cells. J Clin Invest 1991, 87:221-228.

41. Bouman A, Moes H, Heineman MJ, de Leij LF, Faas MM: The immune response during the luteal phase of the ovarian cycle: increasing sensitivity of human monocytes to endotoxin. Fertil Steril 2001, 76:555-559.

42. McGowan PO, Meaney MJ, Szyf M: Diet and the epigenetic (re) programming of phenotypic differences in behavior. Brain Res 2008 1237:12-24.

43. Hiltunen MO, Yla-Herttuala S: DNA methylation, smooth muscle cells, and atherogenesis. Arterioscler Thromb Vasc Biol 2003, 23:1750-1753.

44. Holliday R: The inheritance of epigenetic defects. Science 1987 238:163-170.

45. Sutterlin MW, Bussen SS, Rieger L, Dietl J, Steck T: Serum folate and Vitamin B12 levels in women using modern oral contraceptives (OC) containing 20 microg ethinyl estradiol. Eur J Obstet Gynecol Reprod Biol 2003, 107:57-61

46. Zinellu A, Carru C, Galistu F, Usai MF, Pes GM, Baggio G, Federici G, Deiana L: N-methyl-D-glucamine improves the laser-induced 
fluorescence capillary electrophoresis performance in the total plasma thiols measurement. Electrophoresis 2003, 24:2796-2804.

47. Zinellu A, Sotgia S, Scanu B, Chessa R, Gaspa L, Franconi F, Deiana L, Carru C: Taurine determination by capillary electrophoresis with laserinduced fluorescence detection: from clinical field to quality food applications. Amino Acids 2009, 36:35-41.

48. Zinellu A, Sotgia S, Zinellu E, Pinna A, Carta F, Gaspa L, Deiana L, Carru C: High-throughput CZE-UV determination of arginine and dimethylated arginines in human plasma. Electrophoresis 2007, 28:1942-1948.

49. Esterbauer $\mathrm{H}$, Cheeseman KH: Determination of aldehydic lipid peroxidation products: malonaldehyde and 4-hydroxynonenal. Methods Enzymol 1990, 186:407-421.

50. Sotgia S, Carru C, Franconi F, Fiori PB, Manca S, Pettinato S, Magliona S, Ginanneschi R, Deiana L, Zinellu A: Rapid quantification of total genomic DNA methylation degree by short-end injection capillary zone electrophoresis. J Chromatogr A 2008, 1185:145-150.

51. Brunelleschi S, Penengo L, Lavagno L, Santoro C, Colangelo D, Viano I, Gaudino G: Macrophage stimulating protein (MSP) evokes superoxide anion production by human macrophages of different origin. $\mathrm{Br} J$ Pharmacol 2001, 134:1285-1295.

52. Takeda K, Akira S: Toll-like receptors in innate immunity. Int Immunol 2005, 17:1-14.

doi:10.1186/2042-6410-3-4

Cite this article as: Campesi et al:: Oral contraceptives modify DNA

methylation and monocyte-derived macrophage function. Biology of Sex Differences 2012 3:4.

\section{Submit your next manuscript to BioMed Central and take full advantage of:}

- Convenient online submission

- Thorough peer review

- No space constraints or color figure charges

- Immediate publication on acceptance

- Inclusion in PubMed, CAS, Scopus and Google Scholar

- Research which is freely available for redistribution

Submit your manuscript at www.biomedcentral.com/submit 